\title{
Timespans and Plans Among Young Adults
}

\section{- Michael Anderson}

University of Edinburgh

I Frank Bechhofer

University of Edinburgh

I David McCrone

University of Edinburgh

\section{Lynn Jamieson}

University of Edinburgh

I Yaojun Li

University of Birmingham

\section{Robert Stewart}

Craigforth Consultancy and Research, Stirling

\begin{abstract}
This article uses data from a survey of young adults in Kirkcaldy, Fife, together with associated qualitative interviews, to throw empirical light on their sense of control over their lives and their perceived willingness and ability to plan their lives. Its principal conclusion, contrary to the suggestions of much previous literature, is that a majority of young adults of both genders do, by their early twenties at least, feel in control of their lives and able to exercise forethought over quite long periods of time with respect to many aspects of their futures. Far from seeing the future as simply 'an extended present', they see active opportunities for choice and for formulating their own lives in the years ahead. Only a minority, predominantly those who feel themselves in particularly insecure circumstances, live primarily for the present or think ahead only or principally for the very short term.
\end{abstract}

\section{KEY WORDS}

ambition / career / control / forethought / planning / security / time / young adults 


\section{Introduction}

ver the last ten years there has been a growing body of literature arguing that major structural changes in western societies are introducing much greater diversity into the life-course, especially in its early stages (Allan and Crow, 2001; Berrington and Murphy, 1994; Buck et al., 1994; Bynner et al., 1997; Ermisch, 2000; Furlong and Cartmel, 1997; Pollock, 1997; Taylor, 2000). In principle at any rate, this markedly increases the choices available to individuals and their ability to chart their own routes through life (Beck, 1992; Du Bois-Reymond, 1998; Giddens, 1991). More recently, some writers have taken this still further to suggest that this growth in choice also implies a growth in planning - as Beck-Gernsheim (1996) puts it, life becomes 'a planning project' (and compare Bergmann, 1992; Bandura, 2001).

Others (and indeed some of the same authors in different contexts) argue, by contrast, that while these same changes may indeed offer the hypothetical possibility of choice, this is in practice heavily constrained by lack of resources and structural disadvantage, not least among young people moving out of education and into adult roles (Anderson et al., 2002; Bauman, 1997; Bynner et al., 1997; Furlong and Biggart, 1999; Nilsen and Brannen, 2002). In some views, these problems are exacerbated in a world of so much change and uncertainty with the result that people feel trapped in the present with little sense of real choice or control about their futures even when they may feel that they are making 'decisions' (Sennett, 1998). Under either of these sets of circumstances, it is implied, planning, and particularly long-term planning, will be limited as people lead a life of 'always keeping options open' (Bauman, 1997: 88). A similar argument has also been proposed by writers such as Mayer (1965) and Bergmann (1992) who have argued that planning will only occur where opportunities for choice are superimposed upon a bedrock of security on which one can build, and, even among young adults, by a track record of past success (Anderson et al., 2002; Emimbayer and Mische, 1998; Evans and Heinz, 1993; Heinz et al., 1998). ${ }^{1}$

In a recent article in Sociology, Brannen and Nilsen (2002) argue that, in considering these debates, especially in the context of young adults, we need also to take account of the different ways in which people conceptualize and experience the relationship between the present and the future. At the heart of their discussion is a notion, derived from Nowotny (1994: 50-4), that in contemporary western societies change happens so fast that the future never seems to arrive: 'lived experience is imprisoned in an all pervasive extended present' (Brannen and Nilsen, 2002: 517). In similar vein, Nilsen (1999: 175, 180-1) has argued that 'In societies such as the contemporary western world ... thinking and attention span are aimed at the extended present, or the immediate future', and in this context, apparently in her work almost by definition, 'plans ... can be seen as no more than a short-term projection of the present into the immediate future, or, indeed, as an orientation to the extended present' so that 'the concept of planning' comes to be 'associated with a sense of being in con- 
trol, ... confident in your present situation, and to relate to the extended present rather than the long-term future'.

\section{Background and Data}

Much of the discussion about the impact of recent changes on people's sense of control, and about their willingness to make choices and to plan, seems to be based on intuition, plausibility, or on data from fragmentary or very unrepresentative groups of the population. Brannen and Nilsen (2002) illustrate their discussion with significantly more evidence than most writers in this field, but correctly admit that their six focus groups, comprising various subsets of 18-30-year-olds in Norway and Britain in the later 1990s, can only provide some ideal type examples of the ways in which young people see their present condition and its relationship to their futures. Thus it is very uncertain what proportion of people in the two societies studied match their three models: those with 'extended present time orientations' who live in the present keeping the future at bay; those who approximate more to a model of seeking to forge their own future but by a series of short and tentative steps which they expect to adapt as they go along 'making short-term plans according to changing circumstances' (Brannen et al. 2002: 116); or, finally, those who do indeed see a longer term future but, perversely, see themselves on a clearly charted course which they will follow in sequence with little personal choice because it is similar to that of, or largely at the behest of, their relatives.

In recent years, in a series of studies of what we have come to call 'the exercise of forethought', we have collected a significant, and to the best of our knowledge, unique body of survey data on themes directly relevant to these arguments, particularly with respect to young people and their transition to adulthood, where much of the debate has been concentrated. We do not here seek to repeat findings published elsewhere (Anderson et al., 2002; Li et al., 2002), but rather to look at evidence relating to specific issues raised by a number of authors including Brannen and Nilsen in their various closely related publications: planning and its timespans, and how these relate to gender, resources, and the timing of transitional changes into adulthood.

The data are derived from a survey which we carried out in 1999 in the Kirkcaldy 'travel to work area', 'Telling the Future: Individual and Household Plans among the Younger Adults' (hereafter TTF). We also cite some data from our earlier (1997) survey, 'Individual and Household Strategies: A Decade of Change?' (hereafter DCS). ${ }^{3}$ Both surveys included some questions in selfcompletion booklets, which were filled in separately by the respondent and their partner (if present). The TTF sample consists of 204 randomly selected households containing an adult aged between 20 and 29. There are 110 nonpartnered individuals and 94 couples (all male plus female), but 30 partners in the couple households failed to provide information on most or all items in the questionnaire. The survey thus yielded data on 268 individuals; when, as is 
done throughout here, partners aged less than 20 or 30 and over are excluded, the number of cases falls to 243 .

As a follow-up to the survey, intensive interviews, mostly of between an hour and an hour and a half in length, were conducted with 16 single people and 25 couples, 17 of whom were married and 8 cohabiting. Couples were mostly interviewed together but in two cases one partner was absent for all or most of the interview. The aim of these interviews was to follow up issues raised in the survey with a view to better understanding the content and meanings of some of the responses that were given and also to explore the way in which people saw the relationship between their pasts, presents and futures and the impact of resources and other experiences on their attitudes and ability to plan. Within this context, respondents were selected to illustrate the diversity of experience rather than as any strictly representative subset of the survey interviewees. We also used similar methods alongside our two earlier surveys and, in addition to selected specific examples and quotations included here, our more general comments on and conclusions about the survey data have been informed by our reading of all this material.

The Kirkcaldy area is typical of many areas in Scotland and the UK as a whole in having witnessed a shift over the past 30 years from a declining 'older' economy based largely on heavy industry and manufacturing towards an expanding mixed economy based largely on electronics and the service sector. In 1997, based on official employment rates, the Kirkcaldy 'travel to work area' had slightly higher than average levels of unemployment $(8.6 \%)$ compared to Scottish $(6.8 \%)$ and UK $(5.9 \%)$ rates at the time, and had been consistently above the Scottish and UK rates since 1985.

We cannot, of course, know how representative the foresightful behaviour of Kirkcaldy is of Scotland or the UK as a whole. However, work that we did in the 1980s as part of the Social Change and Economic Life Initiative (SCELI) suggested that the attitudes to planning of people in Kirkcaldy did not then differ sharply from those who lived in the five other areas studied (see also the tables in Gallie and Vogler, 1994: 141-4, and the brief discussion and tables in Gallie, 1996: 164-6). We therefore see no reason to believe that studies in other areas would produce dramatically different results.

\section{Findings}

As we have noted, in line with the predictions of several groups of scholars who have suggested that planning is likely to be limited in the modern world, Brannen and Nilsen use data from their focus groups to suggest that there are only limited subsets of young adults who adopt anything approaching a view of 'life as a planning project' and many who at best proceed by one cautious, uncertain and short-view step at a time, many effectively living 'very much in the present' (Brannen and Nilsen, 2002: 529-31). The gender-segregated nature 
Table I Planspan by gender - cumulative percentages of all

\begin{tabular}{lccc}
\hline & Male & Female & All \\
\hline Plan for: & & & \\
A lifetime & 10 & 8 & 9 \\
A year or more & 28 & 25 & 26 \\
A few months or more & 56 & 57 & 57 \\
A few weeks or more & 75 & 75 & 75 \\
A few days or more & 86 & 90 & 88 \\
Typical N= & 110 & 133 & 243 \\
\hline
\end{tabular}

Table 2 Detail of plans, ambitions and career, by gender - percentages giving a positive response

\begin{tabular}{llll}
\hline & Male & Female & All \\
\hline Make very detailed plans for: & & & \\
Having a job/working & 45 & 35 & 39 \\
Being married/in a relationship & 31 & 31 & 31 \\
Having a better house & 21 & 27 & 24 \\
Holidays/travel & 20 & 17 & 19 \\
Having (more) children & 15 & 13 & 14 \\
Have major ambitions for self/household over next 5 years & 80 & 77 & 78 \\
Have any ambitions for next 10-15 years* & 50 & 38 & 43 \\
See self as having a career* & 78 & 64 & 70 \\
\hline
\end{tabular}

* By $\chi^{2}$, gender differences in Table 2 are significant at the $p<0.05$ level only for those with $10-15$-year ambitions and for seeing oneself as having a career.

of their focus groups also suggests that there may be significant gender differences in planning behaviour.

For our own survey, Tables 1 and 2 review evidence by gender on: the extent and the timespans over which our respondents said that they made plans for some things; the detail in which they made plans; the proportions who said that they had any major ambitions for themselves and their households over the next five years and also any ambitions over a longer 10-15-year timescale; and, as an indication of whether some respondents had a longer term view of where they might be seeking to go in employment terms, the proportions who said that they saw themselves as having a career. ${ }^{4}$

These tables show clearly that almost all our young adult respondents say that they make at least short-term plans and have some ambitions, and that over a quarter make plans for some things a year or more ahead; over half plan for at least a few months ahead. This suggests a large subset making plans with long or very long time perspectives, including several who in the intensive 
interviews laid out well-developed plans that would take them right through to retirement. ${ }^{5}$ Many of our respondents say their plans are 'very detailed', especially in terms of work, relationships and housing. ${ }^{6}$ Above all, the vast majority of these young people think ahead in the long term in the sense of having major ambitions for five, and, for considerable numbers, for 10-15 years ahead. ${ }^{7}$ Also, as we have noted elsewhere (Li et al., 2002), very high proportions, especially of males, see themselves as having a career. ${ }^{8}$ Finally, and contrary to what some other writers may have expected, gender effects on these variables are fairly minimal, confined to long-term ambitions and seeing oneself as having a career, and, more weakly perhaps, to work.

However, not everyone plans, and a quarter of the sample exercise forethought more generally only in the very short term (less than a few weeks at most). As we have shown elsewhere (Anderson et al., 2002) the survey data show that these are disproportionately people with low incomes, burdened with children, frequently unemployed, or whose plans have failed them in the past. ${ }^{9}$ This is backed up by accounts given by respondents in the intensive interviews, nicely illustrated by one 28-year-old machine operator who had clear ambitions for five and 10 years with respect to a new house, promotion and plans for early retirement, but nevertheless only planned a few weeks ahead. When asked 'Why don't you think too far ahead?' he replied 'Trying to get things more secure first!', the problem being that their lives had recently been completely disrupted by an unexpected baby. ${ }^{10}$ However, contrary to what might have been expected by some of those whose views we outline in the introductory discussion, shortterm, low levels of planning are not common among those in this age group who are single or in childless partnerships, and in employment, that is those who make up the majority of this age group in the wider population.

Another feature highlighted in the discussion above was an expectation among some authors that young people in particular would show a very considerable tentativeness and sense of short-term flexibility in their thoughts about the future. Table 3 examines relevant data from our survey. ${ }^{11}$

Certainly, our young adults, and particularly the young men, show a great willingness to modify their plans, though this is somewhat less so for those who make plans over the longer term. However, only a minority are willing to admit to making any plans which are 'really just pipe dreams', and, contrary to what some of the literature might lead us to expect, this is especially unlikely among women with long-term plans. Even more significantly, the vast proportion of our sample show a level of commitment to planning in as far as they believe that it is important that their plans should succeed, and this is particularly so among those who plan for the long term. Nevertheless, there are also some long-term planners who, in the intensive interviews, do indeed change their plans in the light of circumstances. As one 29-year-old semi-skilled manual worker, who said in the survey that he made plans for at least a year ahead, put it: 'I like to analyse situations ... I like to pick my routes, which way I'm going to go. [But] I don't ever do anything irrational or spur of the moment.' We also have evidence on the kinds of things about which they have ambitions. As Table 4 
Table 3 Stability and 'reality' of plans, by gender

\begin{tabular}{llll}
\hline & Male & Female & All \\
\hline Make changes to plans as goes along & & & \\
- all respondents* & 78 & 60 & 68 \\
- long-term planners & 65 & 49 & 56 \\
Also makes plans that are pipe dreams & & & \\
- all respondents & 35 & 37 & 36 \\
- long-term planners* & 52 & 24 & 38 \\
Very/quite important that plans succeed & & & \\
- all respondents & 77 & 74 & 75 \\
- long-term planners & 87 & 85 & 86 \\
\hline
\end{tabular}

Note:This table shows percentages of all respondents, by gender, agreeing with each item, together with responses from 'long-term' planners, i.e. those who say they plan for at least a year ahead.

* By $\chi^{2}$, the gender difference for making changes to plans is significant at the $\mathrm{p}<0.01$ level. The gender difference for plans as pipe dreams, but only among those who plan for a year or more, is significant at the $p<0.05$ level.

Table 4 Detail of 5 year ambitions, by gender - percentages of those with ambitions (or of all childless or not married) giving a 'positive' response

\begin{tabular}{|c|c|c|c|}
\hline & Male & Female & All \\
\hline Promotion/change job/run own business & 43 & 36 & 40 \\
\hline Move/buy house/improve house & 26 & 24 & 25 \\
\hline Get job & II & 21 & 16 \\
\hline Get educational qualifications & 13 & 16 & 14 \\
\hline Get more money & 17 & 10 & 13 \\
\hline Travel/holiday & 15 & 7 & II \\
\hline Typical $\mathrm{N}=$ & 88 & 102 & 190 \\
\hline Have a child (as $\%$ of all childless)* & 3 & 18 & 10 \\
\hline$N=$ & 80 & 94 & 174 \\
\hline Get married (as \% of all not married) & 8 & 5 & 6 \\
\hline$N=$ & 61 & 55 & 116 \\
\hline
\end{tabular}

shows, enhancing one's position at work and housing are the two commonest areas in terms of five-year ambitions. By contrast, the old and more 'traditional' ambition for women of marriage is a very low priority for both genders. So, for childless men, is having a child. ${ }^{12}$

It is, of course, important not to exaggerate the extent of forethoughtfulness of our sample. The overall figures, however, are quite impressive, and they are even more so when they are compared with older groups in the same population from our DCS survey of respondents aged 30 and over. 
For example, the younger TTF group is markedly more likely than older DCS cohorts to have five-year ambitions, more likely to have detailed plans, more likely to see themselves as having a career and more likely to have plans for housing and DIY (for more details see Anderson et al., 2002). They are at least as likely as older groups to plan a year or more ahead, to have 10-15-year ambitions, and to know definitely what they want to do about work over the next five years. It therefore seems highly improbable that these plans of our younger respondents can be seen merely as those of an 'extended present', especially as they share these views of life with large sections of the population from whom much of the literature cited earlier has been at pains to distinguish them.

Overall, it seems to us that, while there are some respondents whose main concern at present is to have a good time or to wait and see, our evidence is better interpreted for large numbers of respondents in terms of a more linear and forward-looking approach. And that, indeed, is also the impression that comes from many of the follow-up qualitative interviews which were conducted with a sub-sample of our study group. In these interviews, many of our young adults clearly describe themselves by using such metaphors as being on a journey to an at least roughly known destination (with the key thing being to look far enough ahead not to 'fall into any huge potholes' as one intensive interview respondent put it), ${ }^{13}$ or climbing a hill in pursuit of fairly concrete aims. By contrast, it was among our older age groups that many were seeking to 'secure their present' by putting up defensive shutters to defend what they have already got. ${ }^{14}$

One possible difference between our data and material used by others who have written on this theme relates to age and educational status. For example, while Brannen and Nilsen's focus groups are drawn from individuals aged 18-30, most of those discussed in their recent article are in their late teens or early twenties and in education or vocational training. The sample we are using here is from the age range 20-29 and rather few are still in education. It seems, however, highly unlikely that age 20 is itself a sufficiently dramatic turning point to explain the differences discussed - and Table 5 throws some possible further light on this by exploring whether there is variation by age within our 20-29 age group. ${ }^{15}$

Almost without exception, the age effects are small. It therefore seems implausible that our findings simply arise because we are dealing with an older age group in a totally different context.

There is another reason why we seriously doubt that our results are different from the expectations of others solely because our respondents are older. Our survey included several retrospective questions, both asking respondents to compare their situation now with what it had been like five years before, and also about their thoughts at age $16 .{ }^{16}$ Certainly, it is relevant to note that two thirds of our respondents aged 23-29 (72\% of those aged 23 or 24 - the question was not asked of those who were younger than this) said that it was now easier to plan compared with five years ago. However, as our earlier discussion has shown, the fact that planning may have been more difficult for this group 
Table 5 Plans ambitions and planspans, by age group - percentages giving a 'positive' response

\begin{tabular}{llll}
\hline & $20-21$ & $22-24$ & $25-29$ \\
\hline Plan for year or more & 34 & 28 & 23 \\
Career & 74 & 69 & 66 \\
Saving for home improvements & 39 & 60 & 62 \\
Saving for new furniture & 30 & 43 & 46 \\
Saving for house deposit & 30 & 17 & 12 \\
5 year ambitions & 84 & 88 & 71 \\
IO-I5 year ambitions & 40 & 47 & 42 \\
Plans very/fairly detailed & 65 & 61 & 50 \\
Stick to plans & 41 & 29 & 32 \\
Several plans at a time & 68 & 68 & 67 \\
Plans that are pipe dreams & 44 & 44 & 29 \\
Very detailed plans for having a job/working & 37 & 38 & 41 \\
Very detailed plans for having a better house & 16 & 25 & 26 \\
5 year ambition to move/buy//improve house & 16 & 24 & 28 \\
ditto for promotion/change job/run own business & 31 & 38 & 43 \\
Savings questions typical N= & 23 & 42 & 95 \\
Other questions typical N= & 38 & 72 & 133 \\
\hline
\end{tabular}

Note: By $\chi^{2}$, none of the differences between ages 20-21 and 22-24 in Table 5 even approach significance at the $\mathrm{p}<0.05$ level.

when they were younger does not seem to have stopped the younger people in our sample from doing it. And certainly it is worth noting that 44 percent of the sample responded 'yes' when they were asked whether they had had any long-term ambitions at age 16 (42\% male, 47\% female) while 51 percent said that they had had a clear idea in their last year at school about the type of job they wanted at, say, age 40 (46\% males, 55\% females).

\section{Conclusion}

In this article we have reported findings on the planning spans of a significantly sized representative sample of young adults collected via a survey questionnaire which was administered in a way which should minimize any possibility that peer pressure might encourage 'false' responses of a short-term and more hedonistic nature. Our intensive follow-up interviews confirm, for a subset of the sample, the broad picture outlined here.

Our conclusions are that very substantial proportions of young adults, at least by the time that they reach the age of 20 , seem to be exercising forethought over quite long periods of time across a wide range of areas of activity. By this age, and at least among those who are childless, whether single or partnered, (and thus among those who are in the most frequently occurring family situa- 
tions for this age group) there are only relatively small numbers whose focus could be construed as being a short-term projection of the present into the immediate future as Nilsen (1999: 180) has implied. And, as we have shown elsewhere (Anderson et al., 2002), many of those with very short timespans of planning are in multiply stressed situations where any possibility of planning for the future is severely hampered by lack of resources and other constraints. Even in this group, however, there are many with clear and quite precise longterm ambitions to change their lives.

The fact, however, that such large numbers of our young adults do plan ahead does not necessarily negate the views of those who argue that the conditions of life in contemporary society are such that it is very difficult for people to deliver their plans. Our interviews do suggest that, whatever they may plan, many of the things that happen to our respondents, of all ages, 'just come up'. On the other hand, as we have shown elsewhere (Anderson et al., 2002), what is interesting about our 1999 survey respondents is that no fewer than 84 percent of them endorsed the view that 'What happens to me is my own doing' rather than the alternative of 'I feel that I have little influence over the things that happen to me'. This was a higher proportion than among the same age group 12 years earlier and much higher than we have seen in any other age group that we have interviewed. What this suggests is that, far from perceiving themselves as being mere pawns in a game of rule-less postmodern chess, a significant number of young adults both know where they want to go and feel able at least to influence how they make active choices between options as they arise.

\section{Acknowledgements}

This article, like all those arising from this project, is the product of a collegiate form of working in which the fieldwork, the analysis and the drafts of the papers have been discussed by the entire research team throughout. The first author has been responsible for initially drafting this article, carrying out analyses and revisions and seeing it into print; the names of the other authors are in random order. The data come from two studies: 'Individual and Household Strategies: A Decade of Change?' (1997) and 'Telling the Future: Individual and Household Plans among the Younger Adults' (1999), funded by the Economic and Social Research Council (ESRC) (R000236922 and R000238020). Michael Anderson, Frank Bechhofer and David McCrone are principal investigators for both studies. Lynn Jamieson joined the second project as principal investigator. Robert Stewart and Yaojun Li were research fellows on both projects. The questionnaires for both surveys were designed by the research team and the fieldwork carried out by Public Attitude Surveys (PAS). We are grateful to the Institute for Social and Economic Research at the University of Essex, and especially Dr Heather Laurie and Dr Jonathan Burton, for helping commission and pilot the surveys, data checking and cleaning, and carrying out the occupational coding. We also thank three anonymous referees for their very helpful comments on an earlier draft. 


\section{Notes}

1 For a more extended discussion of the theoretical background to this article see Anderson et al., 2002.

2 Nilsen goes on (1999: 181) to define 'hopes' as 'areas of life which are beyond control, beyond the extended present' and 'dreams', as 'related to the distant future, if they involve any sense of time at all' and she concludes, with respect to dreams, that "they belong in the sphere of the "unrealistic", that which cannot be related to in a rational manner, that which is totally beyond control'. We find this discussion both conceptually unhelpful and empirically challengeable because, as we show, many members of our sample of young adults both feel in control of their lives, and do have significant concrete long-term plans. It is then also significant that they explicitly distinguish these plans from 'pipedreams'.

3 The DCS survey sought to re-interview as many as possible of 309 respondents first interviewed in Kirkcaldy in 1986 and 1987 as part of the Social Change and Economic Life Initiative, excluding 36 who said in the 1987 survey that they did not wish to be involved further. We traced 220 of the 273 , but further movement and death removed 21 before we commenced interviewing. Of this remaining 199, 180 were successfully re-interviewed. Interviews were also held with partners, where available, and the total number of interviewees was 301 .

4 For full details of the questionnaires used in the study, see the schedules held on-line by the ESRC Data Archive at the University of Essex: www.dataarchive.ac.uk. The wording of the relevant questions here is as in TTF couples: J25-J30, J50, J3, J8 and C50. With respect to timespans of planning, we asked our respondents a sequence of questions, beginning with whether they were someone who at least made plans for a few days ahead at a time, and then, to those who responded positively, a set of questions in which the timescale became progressively longer, up to 'Try to make plans for a lifetime'. The questions on detail of planning were asked in the form of a 10-point scale, with the highest point described as 'Make very detailed plans for this' and the lowest as 'Never make any plans for this'. Only the results for the highest points ['Make very detailed plans for'] are reported in Table 2. Had the top three points been used, the values would have been much higher: for example, 70 percent for having a job/working; 54 percent for being married/in a relationship; and 55 percent for having a better house; but still only 24 percent for having (more) children. The two ambitions questions were worded as: 'Looking ahead over the next five or so years, do you have any major ambitions for yourself or your household?' and 'And do you have any longer-term ambitions, say for the next ten to fifteen years?' The career question was 'Do you see yourself as having a career?'

5 One 25-year-old clerical assistant and her partner detailed wedding plans, followed immediately by children (hopefully twins because they ran in the family), and retirement at 50 after which they would go to Australia; their personal and financial arrangements were all being constructed with these ends in view.

6 For example, one 27-year-old described in his intensive interview the way in which he had quite consciously moved through a series of shop jobs into his present role as account manager for a wholesaler. Looking to the future, he had 
very clear plans for further progression, including taking much more interest in what pensions companies would be offering, though 'maybe not, you know, every job that I'll have from now on will probably be related but might not be with the same. ... It'll be sorta marketing or, communications-based, but maybe not with the same, within the same industry if you like.' With respect to housing, several couples gave accounts of buying houses to do up with the intention of selling at a profit at some already determined point in the future in order to buy something better. As one 27-year-old put it: 'After we sell up this and the profit we make on this one ... can go to another house ... and in that way use it as a stepping stone.' And a number of couples gave detailed accounts of how they planned to relate work and leisure plans to having children, including one 21-year-old woman who was just completing her studies as a nurse and was quite consciously juggling in her mind the pros and cons of job first followed by child or child first on the grounds that she would then be more likely to be considered positively for a job at interview.

7 For example, one 29-year-old man reported that 'we plan a five-year target for doing up the house, ... ripping it to bits and doing bits and bobs that we want to do to it.' And a professional couple in their late 20s, who both reported in the survey that they made plans for at least a year ahead and said in the intensive interview that they were certainly not planning a family in the next five years but would reconsider their situation in about five years' time once the woman was more established in her profession and depending on what career opportunities might come up meantime.

8 This certainly seems contrary to the views of one of Brannen and Nilsen's focus groups who 'expect to be able to try out different types of jobs before they settle down' (Brannen and Nilsen, 2002: 530).

9 For timespan of planning only, however, there is much less structured variation at least in terms of fairly conventional survey variables. This became clear when we ran a logistic regression for both short-term and long-term planning, with income, class, class of origin, age, gender and partnership status as control variables. Of these, income was the only one which was significant at $\mathrm{p}<0.01$ for short-term planning and $\mathrm{p}<0.001$ for long-term planning. Nothing else was significant even at $\mathrm{p}<0.1$. The affluent were around three times less likely to report short-term planning and around four times more likely to report long-term planning.

10 In other areas, a 23 -year-old male packer with some history of unemployment, who still said in the survey that he did not plan even for a few days, reported in the intensive interview that 'there was no plans really until I got made permanent ... because until then I didn't think ... it was important to make any plans. Couldn't build on a maybe if I'm [not] gonna be in work.' Another theme that came through in two intensive interviews as a reason for living from day to day was where respondents knew people who had made detailed plans in the past and had then suddenly died.

11 The wording of the relevant questions here is as in TTF couples: J33, J36 and J35: 'Would you say you are someone who makes a plan and then sticks to it or do you make changes to your plans as you go along?'; 'How important is it to you that your plans succeed? Is it very important, quite important, fairly important, not very important?'; 'Are you the kind of person who also makes plans that you know are really just pipe dreams?' 
12 These answers were given in response to a question as in TTF couples J4, in which respondents who had any five-year ambitions were asked the open-ended question: 'What is it that you would like to do?'

13 Extending this metaphor and showing clear long-term forethought, one 25year-old financial adviser reported that 'I feel like every so often I get stuck in a rut. Every couple of months or every six months or so I feel like I sit down and assess my life, where I'm going, what I'm doing, am I happy where I am, what do I want from my future.'

14 The metaphor of the life course as a journey has been developed by other authors and particularly by Furlong and Cartmel (1997), apparently largely as useful analysts' constructs. Our metaphors are those of our respondents and include a much wider repertoire which, as noted here, includes a number of examples where people, far from seeing themselves as 'going' anywhere, actually see themselves as 'stuck', or as building positions to defend what they have already managed to gain, or to prevent further collapse of their social and resource space.

15 The wording of the relevant questions here is as in TTF couples: J28-30, C50, $\mathrm{H} 21, \mathrm{~J} 3, \mathrm{~J} 8, \mathrm{~J} 31, \mathrm{~J} 33$, J34, J50 and J4. In addition to those summarized above, these were questions which asked those who ever saved which of a list of items they saved for.

16 The wording of the relevant questions here is as in TTF couples: F1, J10 and C16.

17 Our conclusions here derive in part from survey questions in which we have asked respondents about their 'plans' and their 'planning'. We have thus adopted a somewhat different approach from some other writers (such as Nilsen, 1999) who have developed a set of 'sociologists' conceptualizations' of 'planning' and imposed this on their data, in part perhaps influencing their conclusions as a result. In general, our intensive follow-up interviews seem to have confirmed that we and our respondents share a common understanding of what we mean by 'planning'. Nevertheless, in much of our writing in recent years we have ourselves started to move away from the use of the term 'plan' and to set 'plans' within the wider concept of 'forethought'. For present purposes we simply note that the variables that we have employed here to measure timespan of planning have a strong correlation with responses to questions tapping other aspects of forethought, some of which we have also cited above.

\section{References}

Allan, G. and G. Crow (2001) Families, Households and Society. Basingstoke: Palgrave.

Anderson M., F. Bechhofer, L. Jamieson, D. McCrone, Y. Li and R. Stewart (2002) 'Confidence amid Uncertainty: Ambitions and Plans in a Sample of Young Adults', Sociological Research On-line 6(4), URL (consulted Sept. 2004): http://www.socresonline.org.uk/6/4/anderson.html

Bandura, A. (2001) 'Social Cognitive Theory: An Agentic Perspective', Annual Review of Psychology 52: 1-26.

Bauman, Z. (1997) Postmodernity and its Discontents. Cambridge: Polity Press. 
Beck, U. (1992) Risk Society: Towards a New Modernity. London: Sage.

Beck-Gernsheim, E. (1996) 'Life as a Planning Project', in S. Lash, B. Szerszynski and B. Wynne (eds) Risk, Environment and Modernity: Towards a New Ecology, pp. 139-53. London: Sage.

Bergmann, W. (1992) 'The Problem of Time in Sociology', Time and Society 1(1): 81-134.

Berrington, A. and M. Murphy (1994) 'Changes in the Living Arrangements of Young Adults in Britain during the 1980s', European Sociological Review 10(3): 235-57.

Brannen, J. and A. Nilsen (2002) 'Young People's Time Perspectives: From Youth to Adulthood', Sociology 36(3): 513-536.

Brannen, J., C. Kugelberg, M. das Dores Guerreiro and J. Smithson (2002) 'Imagining Parenthood and Employment: Connected or Disconnected Worlds', in J. Brannen, S. Lewis, A. Nilsen and J. Smithson (eds) Young Europeans, Work and Family: Futures in Transition, pp. 116-39. London: Routledge.

Buck, N., J. Gershuny, D. Rose and J. Scott (eds) (1994) Changing Households: The British Household Panel Survey 1990-1992. University of Essex: ESRC Research Centre on Micro-social Change.

Bynner, J., E. Ferri and P. Shepherd (eds) (1997) Twenty Something in the 1990s: Getting on, Getting by, Getting Nowhere. Aldershot: Ashgate.

Du Bois-Reymond, M. (1998) “I Don't Want to Commit Myself Yet”: Young People's Life Concepts', Journal of Youth Studies 1(1): 63-79.

Emimbayer, M. and A. Mische (1998) 'What is Agency?', American Journal of Sociology 103(4): 962-1023.

Ermisch, J. (2000) 'Personal Relationships and Marriage Expectations: Evidence from the 1998 British Household Panel Study', working paper 2000-27. University of Essex: ESRC Research Centre on Micro-social Change.

Evans, K. and W. Heinz (1993) 'Studying Forms of Transition: Methodological Innovation in a Cross-national Study of Youth Transition and Labour Market Entry in England and Germany', Comparative Education 29(2): 145-58.

Furlong, A. and A. Biggart (1999) 'Framing "Choices": A Longitudinal Study of Social Aspirations among 13 to 16-year-olds', Journal of Education and Work 12(1): 21-36.

Furlong, A. and F. Cartmel (1997) Young People and Social Change: Individualization and Risk in Late Modernity. Buckingham: Open University Press.

Gallie, D. (1996) 'Trade Union Allegiance and Decline in British Urban Labour Markets', in D. Gallie, R. Penn and M. Rose (eds) Trade Unionism In Recession, pp.140-74. Oxford: Oxford University Press.

Gallie, D. and C. Vogler (1994) 'Unemployment and Attitudes to Work', in D. Gallie et al., (eds) Social Change and the Experience of Unemployment, pp. 115-53. Oxford: Oxford University Press.

Giddens, A. (1991) Modernity and Self Identity: Self and Society in the Late Modern Age. Cambridge: Polity Press.

Heinz, W.R., U. Kelle, A. Witzel. and J. Zinn (1998) 'Vocational Training and Career Development in Germany: Results from a Longitudinal Study', International Journal of Behavioral Development 22(1): 77-101. 
Li, Y., F. Bechhofer, R. Stewart, D. McCrone, M. Anderson and L. Jamieson (2002) 'A Divided Working Class? Planning and Career Perception in the Service and Working Classes', Work, Employment and Society 16(4): 617-36.

Nilsen, A. (1999) 'Where is the Future?: Time and Space as Categories in the Analysis of Young People's Images of the Future', Innovation, European Journal for the Social Sciences 12(2): 175-94.

Nilsen, A. and J. Brannen. (2002) 'Theorising the Individual-Structure Dynamic', in J. Brannen, S. Lewis, A. Nilsen and J. Smithson (eds) Young Europeans, Work and Family: Futures in Transition, pp. 30-47. London: Routledge.

Nowotny, H. (1994) Time: the Modern and Postmodern Experience. Cambridge: Polity Press.

Pollock, G. (1997) 'Uncertain Futures: Young People in and out of Employment since 1940', Work, Employment and Society 11(4): 615-38.

Sennett, R. (1998) The Corrosion of Character: The Personal Consequences of Work in the New Capitalism. London: Norton.

Taylor, M. (2000) 'Work, Non-work, Jobs and Job Mobility', in R. Berthoud and J. Gershuny (eds) Seven Years in the Lives of British Families, pp. 73-106. Bristol: Policy Press.

\section{Michael Anderson}

Is Professor and Senior Vice-Principal at the University of Edinburgh. His research interests lie in the study of historical and contemporary planning behaviour and in the demographic history of Scotland over the past two centuries. Recent publications include: 'Sooner Rather than Later? Younger and Middle Aged Adults Preparing for Retirement', Ageing and Society 20(4) 2001: 445-66 (with Yaojun Li, Robert Stewart, Frank Bechhofer and David McCrone); 'Population Growth and Population Regulation in Nineteenth Century Rural Scotland', in T. Bengtsson and O.Saito (eds) Population and Economy, pp. I12-131 (Oxford University Press, 200 I); 'One Scotland or Several: the Historical Evolution of Scotland's Population over the Past Century and its Implications for the Future', in Robert Wright (ed) Scotland's Demographic Challenge (Scottish Economic Policy Network, 2004).

Address: School of History and Classics, University of Edinburgh, Old College, North Bridge, Edinburgh EH8 9YL, UK.

E-mail: m.anderson@ed.ac.uk

\section{Frank Bechhofer}

Is Professor and University Fellow at the University of Edinburgh. His current research interests lie in the areas of the study of national identity, especially in Scotland, and continuing work on individual and household strategies. Recent publications include: 'Constructing National Identity: Arts and Landed Elites in Scotland', Sociology 33(3) 
1999: 5 15-34 (with David McCrone, Richard Kiely and Robert Stewart);'Keepers of the Land: Ideology and Identities in the Scottish Rural Elite', Identities: Global Studies in Culture and Power 8(3) 2001: 381-409 (with Richard Kiely, David McCrone and Robert Stewart); 'Confidence amid Uncertainty: Ambitions and Plans in a Sample of Young Adults', Sociological Research On-line 6(4) 2002: http://www.socresonline. org.uk/6/4/anderson.html (with Michael Anderson, Lynn Jamieson, Yaojun Li, David McCrone and Robert Stewart).

\section{David McCrone}

Is Professor and Director of the University of Edinburgh's Institute of Governance. He is currently coordinator of the research programme funded by The Leverhulme Trust on Constitutional Change and National Identity (1999-2004). His recent books include: The Sociology of Nationalism: Tomorrow's Ancestors (Routledge, 1998); Understanding Scotland: the Sociology of a Nation (Routledge, 200I); New Scotland, New Society? (Polygon, 200 I, edited with John Curtice).

\section{Lynn Jamieson}

Is Professor and co-Director of the Centre for Research on Families and Relationships (CRFR) at the University of Edinburgh. Her research interests lie in the study of families and relationships, sexual offences, oral history and issues around identity including 'European identity'. Recent publications include: Intimacy: Personal Relationships in Modern Societies (Cambridge \& Malden, MA: Polity Press, 1998); 'Theorising Identity, Nationality and Citizenship: Implications for European Citizenship Identity', Ç Sociológia: Slovak Sociological Review 34: 507-32; 'Couples and Commitment: Partnership Plans of Young People', Sociological Review 50(3): 356-77 (with Michael Anderson, Frank Bechhofer, David McCrone, Robert Stewart and Yaojun Li).

\section{DrYaojun Li}

Is Lecturer in Sociology and Social Statistics, and Director of MA Social Sciences Research Methods Programmes, School of Social Sciences, University of Birmingham. His research interests are in social mobility and social stratification; political sociology; Sino-British comparisons of class and gender differences; educational and occupational attainment of black and minority ethnic groups in the UK; and statistical analysis and modelling of large-scale and complex social surveys. Recent publications include: 
'Dynamics of Social Capital: Trends and Turnover in Associational Membership in England and Wales, 1972-1999', Sociological Research Online 7(3): 97-132 (with M. Savage, G. Tampubolon, A. Warde and M.Tomlinson); 'Falling off the Ladder? Professional and Managerial Career Trajectories and Unemployment Experiences', European Sociological Review 18(3): 253-70; 'A Divided Working Class? Planning and Career Perception in the Service and Working Classes', Work, Employment and Society 16(4): 617-36 (with Frank Bechhofer, Robert Stewart, David McCrone, Michael Anderson and Lynn Jamieson).

\section{Dr Robert Stewart}

Is a consultant with Craigforth Consultancy and Research, Stirling. His research interests have included issues of national identity and household and individual plans and strategies. Recent publications include: 'Who are We? Problematising National Identity', Sociological Review 46(4): 629-52 (with David McCrone, Richard Kiely, and Frank Bechhofer); 'The Markers and Rules of Scottish National Identity', Sociological Review 49( I), 200 I: 33-55 (with Frank Bechhofer, Richard Kiely, and David McCrone); 'Single, Twenty-something and Seeking' in G. Allan and G. Jones (eds) Time and the Life Course: Age, Generation and Social Change (Palgrave, 2002, pp. 135-54) (with Lynn Jamieson, Michael Anderson, Frank Bechhofer, David McCrone and Yaojun Li). 